\title{
REPRESENTAÇÕES DO ANTISUYU EM EL PRIMER NUEVA CORÓNICA Y BUEN GOBIERNO DE FELIPE GUAMAN POMA DE AYALA
}

\author{
Cristiana Bertazoni Martins \\ Doutoranda do Depto. de História e Teoria da Arte \\ Universidade de Essex - Reino Unido
}

\section{Resumo}

Nas crônicas escritas durante os séculos XVI e XVII no Peru, os Antis (um nome geral usado como termo coletivo para descrever uma grande variedade de grupos étnicos vivendo na parte Amazônica do império), foram representados como rebeldes, não civilizados, bárbaros e até mesmo canibais. Guaman Poma de Ayala reforça esse discurso ambos em seu texto e desenhos onde é possível ver imagens dos Antis vivendo em cavernas e ler sobre suas práticas de antropofagia. Neste pequeno artigo, será estudado o manuscrito de Guaman Poma de Ayala e sua percepcão dos Antis.

\section{Pallavras-Chave}

Amazônia • Antis • Antisuyu • Fontes Históricas Indígenas • Incas • Tahuantinsuyu

\section{Abstract}

In chronicles written during the XVI and XVII centuries the Antis (a general name used as a collective term to describe a great variety of ethnic groups living in the eastern and Amazonian corner of the empire), were portrayed as rebels, uncivilised, sometimes as barbarians and cannibals. Guaman Poma de Ayala reinforces this discourse both in his text and drawings where we can see images of the Antis as Indians living in caves and read about their practicing of anthropophagy. In this short paper I shall focus on the work of Guaman Poma de Ayala and his perception of the Antis.

\section{Keywords}

Amazon • Antis • Antisuyu - Incas - Indigenous Historical Sources • Tahuantinsuyu

\footnotetext{
Bolsista de doutorado pleno no exterior do CNPq.
} 


\section{Introdução}

Nos estudos sobre os povos indígenas da América do Sul existe uma divisão histórica entre os povos das terras baixas e aqueles que se estabeleceram nas terras altas. As antigas culturas que floresceram na região andina são geralmente, e errôneamente, consideradas superiores e mais civilizadas do que os grupos que se estabeleceram na região da Amazônia.

Tahuantinsuyu - os quatro cantos do mundo em quechua - foi um poderoso império comandado pelos Incas e com uma estimativa de quatorze milhões de pessoas sob seu controle em uma área de aproximadamente 2.600 .000 metros quadrados ${ }^{1}$. A coordenação de tão vasto império demonstra a incrível habilidade de organização dos Incas. No entanto, nem tudo era fácil para este império em expansão, já que um de seus suyus, o Antisuyu² (a parte amazônica do império), demonstrou ser extremamente difícil de ser conquistado e teve uma interessante história de ter sido bravamente resistente aos poderosos Incas.

Da mesma forma, nas crônicas escritas durante os séculos dezesseis e dezessete pelos espanhóis e também por índios nativos, os $\mathrm{Antis}^{3}$ - como eram chamados os habitantes do Antisuyu - eram sempre descritos como povos bárbaros, canibais pouco organizados, vivendo em estado de confusão e guerra e sem a liderança de um chefe. Em várias representações pictográficas feitas por Guaman Poma de Ayala, por exemplo, pode ser visto como os Antis foram representados como índios muito simples e que se vestiam com poucas roupas (figuras $2-6$ ).

${ }^{1}$ MORRIS, C. Signs of Division, Symbols of Unity: Art in the Inka Empire. In: Levenson, J. (Ed.) Circa 1492: Art in the Age of Exploration. National Gallery of Art, 1991:521.

${ }^{2}$ Em geral, não existe um consenso em relação às fronteiras do Antisuyu e esforços feitos na tentativa de delimitá-las têm se mostrado bastante difíceis. Por exemplo, Chachapoyas é geralmente considerada como parte do Chinchaysuyu por alguns pesquisadores, porém para outros, é incluída como parte do Antisuyu (ver Parssinen, 1992). No entanto, para Guaman Poma, o Antisuyu se inicia em Cuzco, passando pelas montanhas ao norte até chegar ao Mar del Norte, ou seja, o oceano Atlântico. No mapa-mundi de Guaman Poma (figura 1) pode ser observado que o Antisuyu cobre uma vasta porção de terra desde o sul até o norte do império Inca.

${ }^{3}$ Antis é uma palavra de origem quechua e Andes foi criada pelos espanhóis provavelmente depois de escutarem a palavra Antis. Ambas designam o leste do império Inca e também da cordilheira do Andes ao norte de Cuzco. Antis é um nome usado pelos Incas como um termo coletivo para designar uma grande variedade de grupos étnicos que viviam no Antisuyu, incluindo toda a Amazônia. Será dessa forma que o termo será usado aqui, visto que era assim que a maioria dos cronistas entendiam o termo. 
Nas páginas seguintes, será apresentada uma breve introdução aos principais problemas relacionados ao Antisuyu na intenção de melhor compreendermos a relação que os Incas estabeleceram com os Antis. Em seguida será realizado um pequeno estudo de caso sobre a relação Inca-Antis através do manuscrito El Primer Nueva Corónica y Buen Gobierno escrito por Guaman Poma de Ayala.

\section{Bárbaros e Civilizados}

Por uma série de razões, os estudos sobre o Antisuyu são poucos e marginais e mesmo quando pesquisadores decidiram estudar essa parte do Tahuantinsuyu, as simplificações abundam e, como mencionado, os Antis foram muitas vezes vistos de uma forma ultra simplificada e são geralmente classificados como povos que nunca conheceram a civilização - em contraposição aos povos considerados civilizados da região andina - e que viviam em um ambiente extremamente hostil e com baixa potencialidade para a agricultura. ${ }^{4}$ Além das crônicas escritas, logo após a conquista espanhola da área andina, esta divisão marcada entre terras altas e baixas também pode ser facilmente observada ao analisarmos um dos mais famosos compêndios sobre os índios da América do Sul. Organizado e editado por J. H. Steward, o Handbook of South American Indians ${ }^{5}$ - por muito tempo e até hoje considerado como uma bíblia para qualquer pesquisador sobre os índios da América do Sul claramente divide terras baixas e terras altas. A divisão do Handbook é a seguinte: tribos marginais, culturas da floresta tropical, cacicados do circumCaribe, regiões sub-andinas e civilizações andinas. Obviamente, pressupõese uma hierarquia nessa classificação que começa com as tribos marginais e atinge o ápice da civilização, de acordo com o Handbook, com os povos das

\footnotetext{
${ }^{4}$ Para uma discussão sobre as limitações agrícolas da Amazônia ver MEGGERS, B. J. Environmental Limitations on the Development of Culture. American Anthropologist, New Series, 1954, Vol. 56, N. 5, Part 1:801-824. Para uma resposta e discussão alternativa sobre o determinismo ecológico sugerido por Meggers, ver MYERS, T. P. Agricultural Limitations of the Amazon in theory and Practice. The Humid Tropics. World Archaeology. Jun., 1992, Vol. 24, No. 1: 82-97. Sobre a reação de estudiosos da Mesoamérica em relação ao determinismo ecológico ver COE, M. Social Typology and the Tropical Forest Civilizations. Comparative Studies in Society and History, 1961, 4 (1):65-85.

${ }^{5}$ STEWARD, J. (Ed.). Handbook of South American Indians. Washington D.C.: Smithsonian Institution, 1948.
} 
terras altas como Chávin, Chimú e os Incas. Poderia-se argumentar que tal divisão foi realizada por questões de organização do Handbook porém, pouquíssimos artigos de seus vários volumes entendem a região andina e a região amazônica como sendo parte de uma mesma história.

Outro fator que vale a pena colocar na intenção de melhor compreendermos a relação Incas-Antis é que, como mencionado anteriormente, os Incas nunca conseguiram conquistar o Antisuyu por completo. Alguns pesquisado$\operatorname{res}^{6}$ acreditam que uma das principais razões para tanto foram as diferenças socioculturais e políticas bastante diferentes entre os povos do Antisuyu e os Incas. A estrutura hierárquica deste ultimo era bastante rígida e o seu poder acentuadamente centralizado, características que teriam tornado difícil à adesão dos povos amazônicos que tinham uma organização social bastante diferente dos Incas. Porém, outros autores ${ }^{7}$, acreditam que essa teoria sugere pouca valorização de positivas conquistas Incas de alguns grupos que viviam à leste do império. Já Levellier ${ }^{8}$ sugere que os Incas jamais conseguiram conquistar os Antis devido à agressividade desses últimos, o que explicaria a construção de várias fortalezas Incas na região do Antisuyu.

Dado um significativo número de fortalezas Incas à leste do império, acredito que mesmo que o Antisuyu tenha sido a região em que os Incas tiveram mais dificuldades em conquistar, não poderia ser negado que o Tahuantinsuyu teve uma participação marcante nas terras dos Antis. Até muito recentemente, acreditava-se que quase não existia uma presença Inca no Antisuyu, porém, novas descobertas nos forçam a repensar essa situação. Um exemplo da presença Inca em solo amazônico é a fortaleza de Las Piedras em Ribeiralta, próxima a junção entre os rios Beni e Madre de Dios, perto da fronteira do Peru e Brasil ${ }^{9}$. Acredito que a região da selva não era um território desconhecido para os Incas, estes conheciam bem a sua geografia (ver Mapamundi de

\footnotetext{
${ }^{6}$ SANTOS, F. Etnohistoria de la Alta Amazônia. Siglos XVI-XVIII. Equador: Editora AbyaYala, 1992.

${ }^{7}$ TAYLOR, A. C. The Western Margins of Amazonia from the Early Sixteenth to Early Nineteenth Century. In: SALOMON, F. \& SCHWARTZ, S. B. (Eds.) The Cambridge History Of Native Peoples of Americas, South America: Escuela de Estudios Hispano-Americanos de Sevilla, 1956. ${ }^{9}$ PÄRSSINEN, M. \& KORPISAARI, A. (eds.). Western Amazonia. Amazônia Ocidental. Multidisciplinary Studies on Ancient Expansionistic Movements, Fortifications and Sedentary Life. Renwall Institute Publications 14. University of Helsinki, 2003.
} 
Guaman Poma, figura 1), variedade cultural e principalmente seu potencial para prover produtos que eram de extremo interesse para o bom funcionamento de um império em plena expansão como, por exemplo, folhas de coca, plumas e madeira.

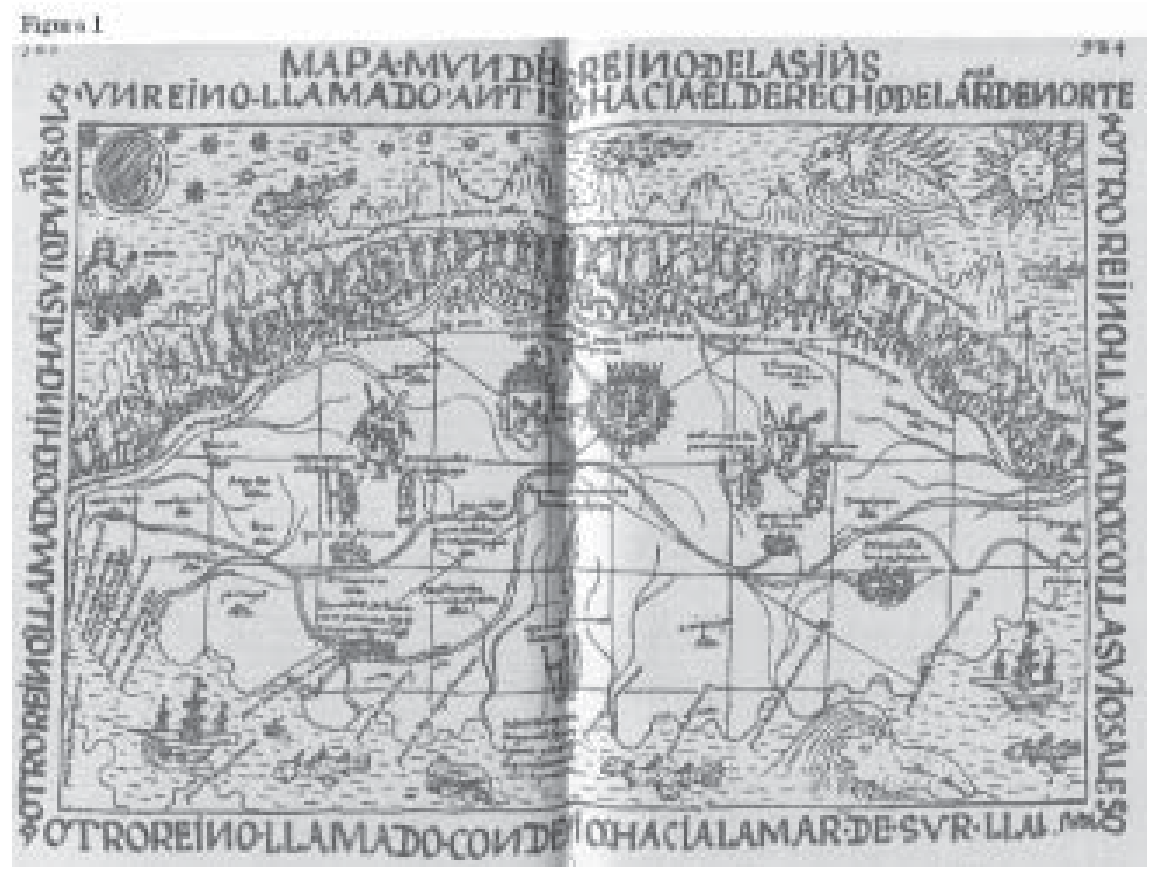

Podemos estar ainda longe de compreendermos as razões pelas quais o Antisuyu foi apenas parcialmente conquistado pelos Incas. Porém, acreditar que este fato ocorreu por falta de conhecimento da selva por parte destes últimos, talvez não seja o caminho mais interessante a seguir.

\section{Hostilidade e Harmonia: 0 Oposto como Necessidade}

De acordo com Tom Zuidema ${ }^{10}$, a estrutura social Inca era baseada no sistema de ceque em que o mundo estava dividido simultâneamente em duas

\footnotetext{
${ }^{10}$ ZUIDEMA, T. El Sistema de Ceques del Cuzco. La Organización de la Capital de los Incas. Lima: Fondo Editorial de la PUC-Peru, 1995.
} 
partes (Hanan e Hurin), três partes (collana, payan, cayao) e em quatro partes (Chinchaysuyu, Antisuyu, Collasuyu e Cuntisuyu). Cuzco estava no centro deste sistema e representava o lugar mais sagrado e importante do Tahuantinsuyu. Chinchaysuyu representava o primeiro e mais importante suyu do império, pois era ao mesmo tempo Hanan e Payana. No entanto, como colocado por Adorno ${ }^{11}$, deve ser enfatizado que esta dicotomia entre superioridade e inferioridade não significa valores absolutos mas, ao contrário, articulava um sistema de oposições e uma hierarquia de preferências. Segundo Adorno, a qualidade de complementaridade dos termos opostos é central nesta relação e o conceito de oposição é substantivo porque é estrutural.

Ambos Chinchaysuyu e Antisuyu eram considerados Hanan (parte de cima), enquanto que Collasuyu e Cuntisuyu eram Hurin (parte de baixo). Além disso, como todo suyu do império, Chinchaysuyu tinha seu oposto representado pelo Antisuyu. Nesse caso, Antisuyu era Hurin e Chinchaysuyu representava Hanan. Logo, Antisuyu era logicamente uma parte essencial e intrínseca do mundo Inca: para que a visão cósmica Inca fosse completa, a existência do Antisuyu, como a de qualquer outro suyu, era fundamental. ${ }^{12}$

Chinchaysuyu e Antisuyu eram dois opostos que, ao mesmo tempo, se complementavam e dependiam um do outro. O primeiro era o lugar da alta hierarquia Inca, símbolo de civilização, organização e poder centralizado. O segundo, era o suyu do caos, da ausência de civilização e ordem. Dentro do mundo Inca, funcionavam como opostos: masculino/feminino, alto/baixo, seco/ molhado, civilizado/não-civilizado, organizado/caótico. Em uma palavra, eram dois contrários que se complementavam. Sem um, o outro não existia.

Taylor $^{13}$, acredita que muitos aspectos da mitologia e iconografia Inca sugerem que a selva funcionava como um elemento de complementaridade e como um elemento de identidade hierarquicamente ordenado em que existia

\footnotetext{
${ }^{11}$ ADORNO, R. Guaman Poma. Writing and Resistance in Colonial Peru. Institute of Latin American Studies, University of Texas Press, 1986.

${ }^{12}$ Para uma discussão detalhada sobre o sistema de ceques Inca, ver ZUIDEMA, T. El Sistema de Ceques del Cuzco. La Organización de la Capital de los Incas. Lima: Fondo Editorial de la PUC-Peru, 1995.

${ }^{13}$ TAYLOR, A. C. The Western Margins of Amazonia from the Early Sixteenth to Early Nineteenth Century. In: SALOMON, F. \& SCHWARTZ, S. B. (Eds.) The Cambridge History of Native Peoples of Americas, South America III.Cambridge University Press, 1999:188-256.
} 
oposição entre um macho superior andino e uma fêmea inferior e ameaçadora representada pela selva. ${ }^{14}$

Os exemplos acima sugerem que ao contrário de uma eterna hostilidade e profundo antagonismo entre os Incas e os povos da floresta tropical, havia fortes relações históricas entre eles. No entanto, a idéia de uma perfeita e harmoniosa união entre as duas partes - terras altas e terras baixas ou Chinchaysuyu e Antisuyu - pode ser tão perigosa quanto o completo divórcio.

\section{Sobre Felipe Guaman Poma de Ayala}

Muito pouco é conhecido a respeito do autor de El Primer Nueva Corónica y Buen Gobierno além do que ele mesmo nos informa em seu manuscrito.

Guaman Poma foi um índio nativo cujo pai pertenceu a uma família nobre de Huánuco, na atual região de Ayacucho, Peru. Segundo ele, sua mãe era filha de Tupac Yupamqui, o décimo Inca. Sua data de nascimento é desconhecida e seu falecimento ocorreu provavelmente logo após 1615.

Guaman Poma foi introduzido à fé cristã durante sua infância quando estava aprendendo a ler e escrever. Anos mais tarde, quando já adulto, o autor trabalhou como intérprete para os espanhóis, além de ter se engajado em ensinar espanhol para os nativos na tentativa de ajudá-los a se defender dos europeus e ao mesmo tempo resistir à colonização ${ }^{15}$. Guaman Poma soube muito bem como capitalizar sua experiência de trabalho com os espanhóis para, mais tarde, manipular os códigos europeus e denunciar os abusos da empresa colonizadora européia no Peru.

Através de seu manuscrito, Guaman Poma critica fortemente o comportamento dos espanhóis que por anos exploraram os nativos de várias maneiras. De fato, uma das principais preocupações de Guaman Poma ao escrever $E l$ Primer Nueva Corónica y Buen Gobierno era condenar todo e qualquer tipo de abuso ou exploração praticados pelos espanhóis em detrimento dos indígenas.

\footnotetext{
${ }^{14}$ Análises baseadas em oposições binárias entre as terras baixas e altas influenciaram muitos estudos sobre o tema. Porém, apesar das contribuições oferecidas, estas análises não representam o entendimento indígena sobre as duas áreas (terras altas e baixas). Pelo contrário, tais oposições parecem representar uma simplificaçao ocidental de um rol de problemas muito mais complexo.

${ }^{15}$ ADORNO, R. Don Felipe Guaman Poma de Ayala: Author and Prince. In: Guaman Poma de Ayala. The Colonial Art of an Andean Author. New York, Americas Society, 1992:10.
} 


\section{Sobre El Primer Nueva Corónica y Buen Gobierno}

Como um exercício ou estudo de caso na tentativa de observar a relação Inca-Antis, El Primer Nueva Corónica y Buen Gobierno escrito por Guaman Poma de Ayala se diferencia dos demais manuscritos de sua época por uma série de razões. Em primeiro lugar, este texto se sobressai pois, além de sua parte textual contém também cerca de 400 imagens feitas pelo autor. Além disso, Guaman Poma afirma que El Primer Nueva Corónica y Buen Gobierno foi transcrito de um Khipu ${ }^{16}$, o que nos oferece um relato mais direto, sem filtros e mais próximo a visão de mundo andina. Sem contar que é também um extenso e detalhado documento escrito sobre a sociedade e tradições Inca.

Inicialmente, Guaman Poma escreveu seu manuscrito como uma carta ao rei Felipe III da Espanha. Não há evidências de que El Primer Nueva Corónica y Buen Gobierno tenha chegado às mãos do rei. Porém, em 1908 o manuscrito foi encontrado na Dinamarca por Richard Pietschman e foi publicado pela primeira vez em 1936 graças ao arqueólogo francês Paul Rivet. O texto consiste de três partes: a primeira chamada de El Primer Nueva Corónica na qual oferece uma descrição do governo Inca, seus ritos, tradições, genealogia, entre outros; a segunda parte trata sobre a conquista espanhola e finalmente, a terceira e última parte chamada de Buen Gobierno oferece ao rei conselhos sobre um possível 'bom governo' - que levasse mais em conta os direitos dos

\footnotetext{
${ }^{16}$ Khipu era um aparato administrativo constituído de cordões coloridos e nós e que serviam para contabilizar objetos e também fatos históricos. Existem aproximadamente 600 khipus que sobreviveram desde a época da conquista. Infelizmente, dado as enormes diferenças entre os khipus e os meios tradicionais de pensamento e representação da escrita ocidental, o conhecimento de como se ler um khipu foi perdido. Desde tempos coloniais existe um debate se os khipus eram apenas um instrumento nemônico ou se também constituíam uma forma de escrita. Segundo Brokaw, a complexa natureza tri-dimensional dos khipus possibilitava ao seu leitor - khipucamayoc - uma variedade de leituras convencionais as quais não há paralelo nos sistemas lineares de leituras alfabéticas (2003:138). Ainda segundo Brokaw, o fato de que culturas são geralmente classificadas entre históricas (aquelas que usam a escrita) e pré-históricas (sem escrita), cria uma oposição entre escrita e oralidade o que não permite espaço para outras formas alternativas de representação como no caso dos khipus (2003:140-141). Recentemente, Gary Urton da Harvard University, embarcou em um projeto ambicioso para tentar decifrar os khipus (para mais informações veja a página do Khipu Database Project no endereço http://khipukamayuq.fas.harvard.edu).
} 
nativos - a ser implantado no Peru. No entanto, além dessas três divisões aparentes, muitas outras sub-divisões internas podem ser observadas ${ }^{17}$.

A primeira vista, o leitor incauto pode se frustrar com a aparente incoerência de organização dos capítulos e também com alguns erros de espanhol. No entanto, o grande potencial de El Primer Nueva Corónica não se encontra na competência do autor com a língua espanhola e muito menos na organização de capítulos em um formato que satisfaria o olhar ocidental. Pelo contrário, a reconstrução histórica de Guaman Poma longe de representar uma narrativa caótica, é uma síntese elaborada de acordo com a lógica indígena ${ }^{18}$. Assim sendo, os pontos mais fortes de El Primer Nueva Corónica y Buen Gobierno são justamente sua proximidade da tradição indígena de pensamento e a forma como Guaman Poma domestica a tradição européia baseada em livros paginados (inicialmente um formato pouco familiar ao autor) preenchendo cada página de seu manuscrito de uma maneira inteligente, criando não somente um texto informativo sobre as tradições Incas, mas também uma obra de arte visual.

Este extraordinário manuscrito de aproximadamente 1.200 páginas e cerca de 400 desenhos, combina texto e imagens na tentativa de descrever ambos os governos Inca e espanhol. Para quase cada página escrita por Guaman Poma há um desenho correspondente. Estas imagens, no entanto, estão longe de ser meras ilustrações do manuscrito, mas funcionam como textos que podem e devem ser lidos como tal, da mesma forma que seu texto também pode e deve ser observado visualmente. Ou seja, do mesmo modo como as imagens do manuscrito podem ser lidas como texto $^{19}$, Valerie Fraser sugere que algumas das páginas do texto também devem ser entendidas como imagens. Para a autora, a intenção de Guaman Poma era criar um todo unificado em que o leitor é encorajado a se alternar fluentemente entre categorias, onde imagens incluem palavras e, em alguns casos, palavras são imagens. ${ }^{20}$

\footnotetext{
${ }^{17}$ BROKAW, G. The Poetics of Khipu Historiography: Felipe Guaman Poma de Ayala's Nueva Corónica and the Relación de los Quipucamayos. Latin American Research Review, Vol. 38. N. 3, October 2003:111-147.

${ }^{18}$ WACHTEL, N. Sociedad e Ideologia. Ensayos de Historia y Antropologia Andinas. Lima, Instituto de Estudios Peruanos, 1973.

${ }^{19}$ ADORNO, R. Don Felipe Guaman Poma de Ayala: Author and Prince. In: Guaman Poma de Ayala. The Colonial Art of an Andean Author. New York, Americas Society, 1992:32-45 e CUMMINS, T. The Unconfortable Image: Pictures and Words in the Nueva Corónica y Buen Gobierno. In: Guaman Poma de Ayala. The Colonial Art of an Andean Author. New York, Americas Society, 1992:46-59.

${ }^{20}$ FRASER, V. The artistry of Guaman Poma. Res 1996, 29-30:274.
} 
Na intenção de melhor compreender esta fusão de duas tradições diferentes de escrita ou a combinação de elementos europeus e indígenas presentes no manuscrito de Guaman Poma, o conceito de zonas de contato textuais sugerido por Brokaw ${ }^{21}$ pode ser bastante útil para o estudo de El Primer Nueva Corónica y Buen Gobierno.

$\mathrm{O}$ conceito de zonas de contato foi definido por Mary Louise Pratt ${ }^{22}$ como espaços sociais onde diferentes culturas se encontram e colidem umas com as outras, geralmente em relações altamente assimétricas de dominação e subordinação. De uma forma bastante interessante, Brokaw modifica o conceito de zonas de contato de Pratt e o transforma em zonas de contato textuais em que distintos modos culturais e convenções de representação se encontram e colidem entre eles e, da mesma forma, através de relações altamente assimétricas de dominação e subordinação. Brokaw sugere que no manuscrito de Guaman Poma dois diferentes princípios meta-textuais convergem - um baseado nas regras e princípios literárias européias e um segundo baseado na tradição indígena andina numérica e textual, ou seja, os khipus. ${ }^{23}$

\section{Representações Imperiais do Antisuyu}

Em primeiro lugar, existem alguns problemas em afirmar que Guaman Poma seria um representante do ponto de vista Inca em relação ao Antisuyu. A visão de Guaman Poma pode ser considerada como anti-Inca em diversas formas, particularmente quando ele afirma que o direito de governar a região andina deveria ser dada ao seu próprio clã, Yarovilca, e não aos Incas. E também quando o autor claramente deprecia o primeiro Inca, Manco Capac e sua mãe, Mama Uaco. ${ }^{24}$ Porém, parece-me que inevitavelmente a perspectiva de

\footnotetext{
${ }^{21}$ BROKAW, G. Khipu Numeracy and Alphabetic Literacy in the Andes: Felipe Guaman Poma de Ayala's Nueva Corónica y Buen Gobierno. Colonial Latin American Review, Vol. 11, N. 2, 2002:276.

${ }^{22}$ PRATT, M. L. Imperial Eyes: Travel Writing and Transculturation. London: Routledge, 1992.

${ }^{23}$ BROKAW, G. Khipu Numeracy and Alphabetic Literacy in the Andes: Felipe Guaman Poma de Ayala's Nueva Corónica y Buen Gobierno. Colonial Latin American Review, Vol. 11, N. 2, 2002:276.

24 "El dicho primer Ynga Manco Capac no tubo padre conocido; por esso le digeron hijo del sol, Ynti Churin, Quillap Uauan (filho do sol e da lua). Pero de uerdad fue su madre Mama Uaco. Esta dicha mujer dizen que fue gran fingedora, ydúlatra, hichisera. Y ací hazía hablar piedras y peñas y palos y zerrosy lagunas porque le rrespondía los demonios del ynfierno y hazía serimonias y hecheserías" AYALA, GUAMAN POMA (1615) El Primer Nueva Corónica y Buen Gobierno. México: Siglo Vientiuno, 1980, p. 63.
} 
Guaman Poma corresponde com a visão de mundo Inca em vários aspectos, afinal, sua família foi totalmente assimilada dentro da administração Inca e, além disso, várias partes de seu manuscrito estão de acordo com uma visão de mundo particularmente Inca como, por exemplo, a maneira em que o autor descreve as cinco idades do mundo. De fato, as imagens criadas por Guaman Poma ao narrar as idades do mundo reforçam a ideologia Inca de trabalho e progresso na qual, segundo Brotherston, ${ }^{25}$ à humanidade é oferecida a chance de ascensão ao custo da obediência Inca. Assim sendo, não me parece equivocado afirmar que a visão de Guaman Poma sobre o Antisuyu estava de acordo com o ponto de vista Inca.

Para iniciarmos a análise do manuscrito de Guaman Poma, vale a pena começar por um de seus mais interessantes desenhos, o Mapamundi del Reino de las Indias (figura 1). Este mapa engenhosamente combina duas tradições cartográficas bastante diferentes de mapear o mundo: a tradição Incaandina de dividir o mundo em quatro partes com Cuzco ao centro; e a tradição européia evidenciada pela adição de áreas além do mundo andino. ${ }^{26}$

No mapa de Guaman Poma é possível observar ambos os oceanos Pacífico (Mar del Sur) e Atlântico (Mar del Norte) nos extremos sul e norte. O Mapamundi de Guaman Poma sofreu, no entanto, uma rotação anti-horária de 90 graus, bastante diferente da cartografia européia. Assim sendo, no mapa em questão, leste se torna norte, oeste se transforma em sul e assim por diante. Dessa forma, a parte Amazônica do império, ou seja, o Antisuyu que nos mapas ocidentais se encontra a leste, agora se situa ao norte.

Ao colocar a capital Inca, Cuzco, exatamente no centro de seu mapa, o sul é então representado pelo Condesuyu; leste pelo Collasuyu; oeste pelo Chinchaysuyu e finalmente o norte pelo Antisuyu. O eixo leste-oeste representa as parte do império em que os Incas mais expandiram. O sul não poderia se estender mais por razões óbvias já que termina no oceano Pacífico. Finalmente, a parte norte do Tahuantinsuyu estava entre os territórios que os Incas tiveram mais problemas em conquistar, o Antisuyu que sempre representou para os Incas um projeto de integração nunca alcançado.

\footnotetext{
${ }^{25}$ BROTHERSTON, G. Book of The Fourth World. Reading The Native Americas through their Literature. Cambridge University Press, 1992:254.

${ }^{26}$ BROTHERSTON, G. Book of The Fourth World. Reading The Native Americas through their Literature. Cambridge University Press, 1992.
} 
De leste a oeste, toda a parte norte do Mapamundi de Guaman Poma é dominado por uma densa barreira de árvores, rios caudalosos e uma fauna exuberante. Em El Primer Nueva Corónica y Buen Gobierno - e em diversas outras crônicas - a idéia de um ambiente selvagem e não domesticado pelo homem, animais ferozes, canibalismo, ausência de civilização e ordem é desproporcionadamente relacionada ao Antisuyu.

Ao olharmos mais de perto para o manuscrito em questão pode-se facilmente observar como o Antisuyu e seus habitantes foram representados de uma maneira bastante diferente dos demais suyus. Evidências dessas representações distintas podem ser encontradas no momento em que Guaman Poma trata dos capitães Incas (Capacs), das senhoras (Collas), dos lugares sagrados (huacas), dos festivais e das cerimônias de enterramento através dos quatro cantos do Tahuantinsuyu.

É interessante destacar que a estrutura de El Primer Nueva Corónica y Buen Gobierno segue um padrão em que os quatro suyus são descritos de forma sistemática e geralmente seguem uma ordem em que, muito freqüentemente, a capital do império, Cuzco, também é incluída. Em primeiro lugar Guaman Poma sempre descreve Cuzco (quando este é incluído), seguido do suyu mais importante do império, ou seja, o Chinchaysuyu, em seguida Antisuyu, Collasuyu e finalmente Cuntisuyu. Essa ordem parece estar de acordo com a hierarquia do sistema de ceques Inca mencionada acima.

De acordo com Guaman Poma, havia quinze capitães Inca - Capacs - nos quais o autor descreve em detalhes. O sexto e o décimo terceiro capitães são os únicos que foram claramente representados de uma forma distinta dos demais suyus, em um ambiente de selva e vestindo poucas roupas (figura 2).

Otorongo Achachi ${ }^{27}$ Apo Camac Inga, o sexto capitão é representado de uma maneira bastante peculiar: como uma figura zoomorfa que tem o corpo de um jaguar e um rosto que é metade de humano, metade de jaguar. De acordo com Guaman Poma, Otorongo Achachi era filho de Ynca Roca e se transformou em um jaguar para poder conquistar o Antisuyu. Nesta imagem, um índio Anti com seu arco e flecha mal pode ser visto já que Otorongo está localizado no centro da página rodeado por árvores que o autor chama de chunta.

${ }^{27}$ Otorongo significa jaguar em quechua e Achachi é uma palavra Aymara que indica descendência patrilinear. 
Figura 2

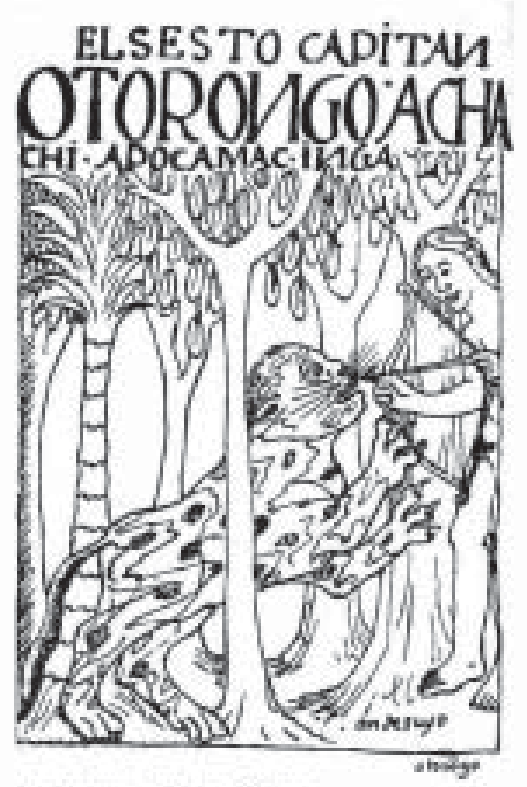

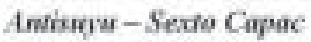

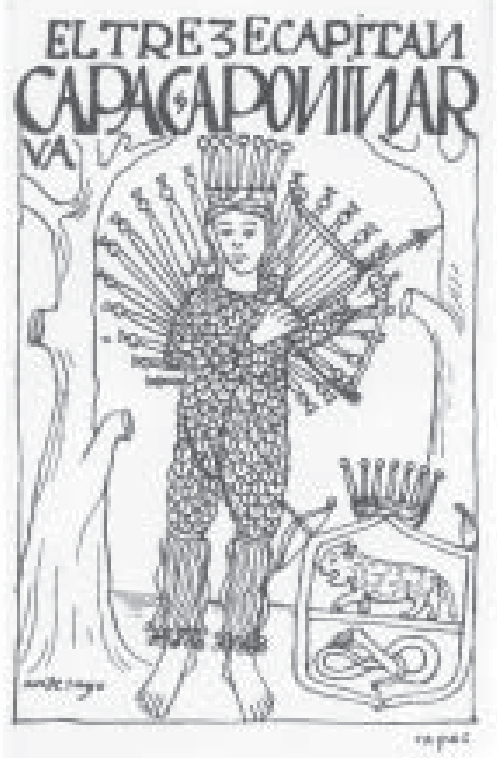

Antisayu - Déciuno Tercaino Capac

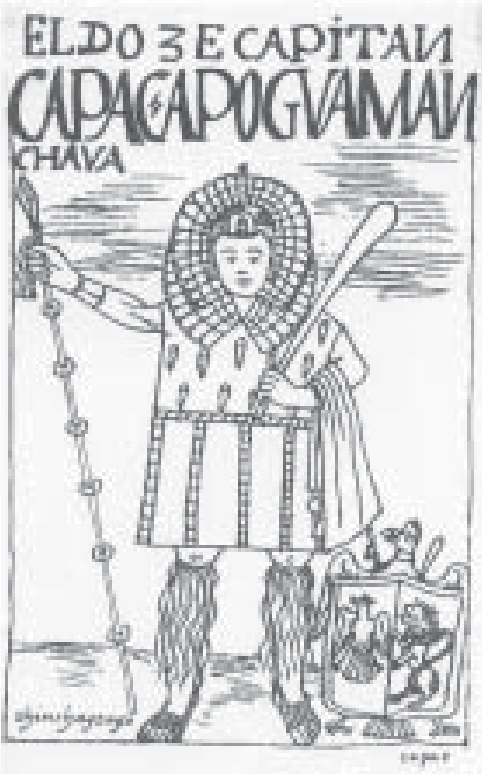

Chinchrosugu - Décimo Segando Capac

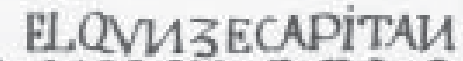

MALLCOMVLLO

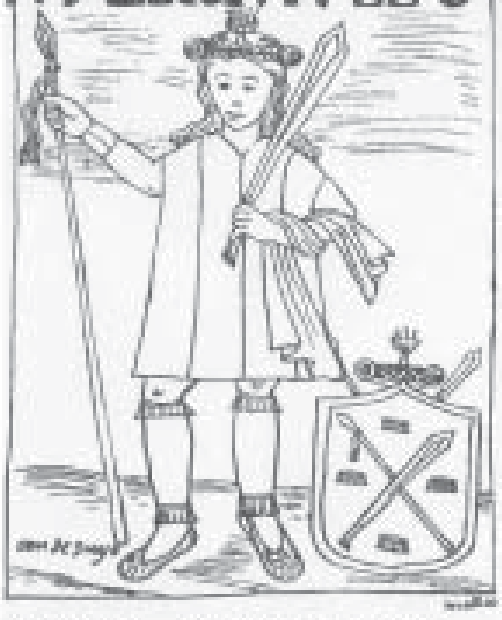

Conderuya-Décime Qhinre Capac 
Importante colocar que a chunta (palmeira em quechua) é uma árvore da família das palmeiras muito usada pelos Antis para a confecção de arco e flecha devido sua alta elasticidade. Os Incas não utilizavam arcos e flechas, pois palmeiras somente podem ser encontradas na região do Antisuyu.

Apo Ninarva, o décimo terceiro capitão também esta relacionado com o Antisuyu e de modo similar a Otorongo Achachi, está representado com um arco e flecha entre duas árvores. Ninarva está vestido com plumas (um elemento proveniente do Antisuyu) que também podem ser vistas em seu diadema e em suas costas. No chão, a sua esquerda, pode ser visto um emblema com dois personagens típicos do Antisuyu: um jaguar na parte superior e uma cobra na parte inferior.

No caso de todos os outros capitães Guaman Poma sempre descreve suas qualidades, defeitos e personalidade. No entanto, no caso de Otorongo Achachi e Apo Ninarva o autor preferiu não escrever suas respectivas personalidades e, ao contrário, se dedicou a uma descrição dos povos de suas terras, ou seja, o Antisuyu e os Antis. Sobre esse último, Guaman Poma enfatiza a prática do canibalismo, sua nudez e infidelidade em relação aos imperadores Inca.

Imediatamente após descrever sobre os capitães de Tahuantinsuyu, Guaman Poma dedica algumas páginas às quatro senhoras do império.

A primeira a ser representada é Capac Poma Gvallca, a avó de Guaman Poma. Ela é do Chinchaysuyu, mais especificamente, de Yarovilca. Tanto Capac Poma Gvallca como as demais senhoras ou collas são representadas pelo autor com roupas e em um ambiente sem interferências (figura 4). Já no caso de Capac Mallquina, a senhora do Antisuyu, está representada com seu corpo semi-nu, rodeada por árvores, com um pássaro a sua esquerda e, a sua direita, um macaco que toca sua perna. De acordo com o texto de Guaman Poma, Capac Poma Gvallca é muito bonita e mais branca do que os próprios espanhóis, porém, come carne humana e anda semi-nua. Estes dois últimos são elementos que claramente depreciam Capac Poma Gvallca e também os Antis. Principalmente se lembrarmos que El Primer Nueva Corónica y Buen Gobierno foi escrita a um rei cristão para quem roupas e vestimentas representavam um dos elementos mais básicos de uma sociedade civilizada. Além disso, o canibalismo dos Antis descrito por Guaman Poma pode ter reforçado a idéia de superioridade cultural européia e assim colaborado para justificar a invasão e colonização do Peru.

Mais adiante em seu manuscrito, Guaman Poma continua suas descrições de como grupos dos quatro cantos do império conduziam seus funerais (figura 3). 
Figura 3

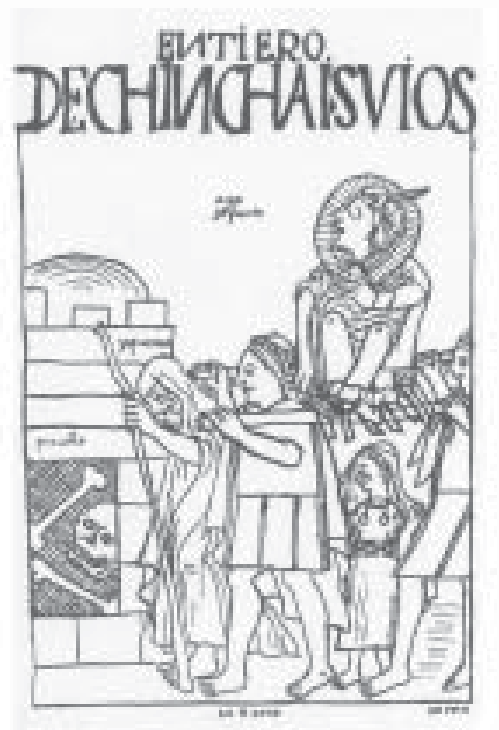

Chinchaysayu - Enacrramentos

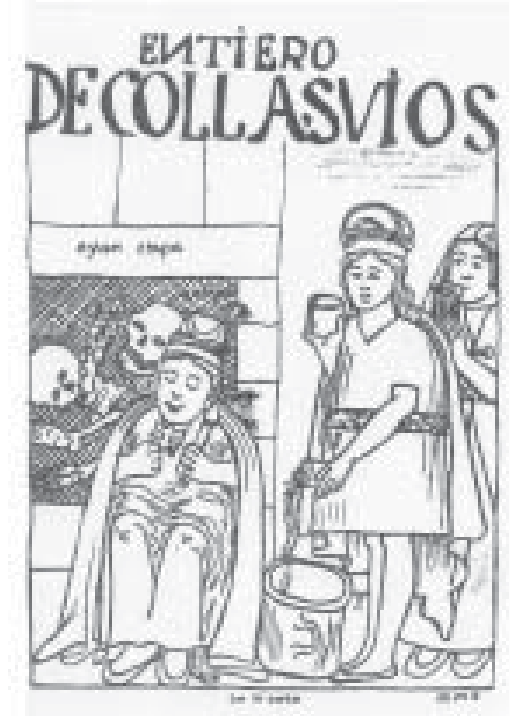

Collasuyw - Earemamentos
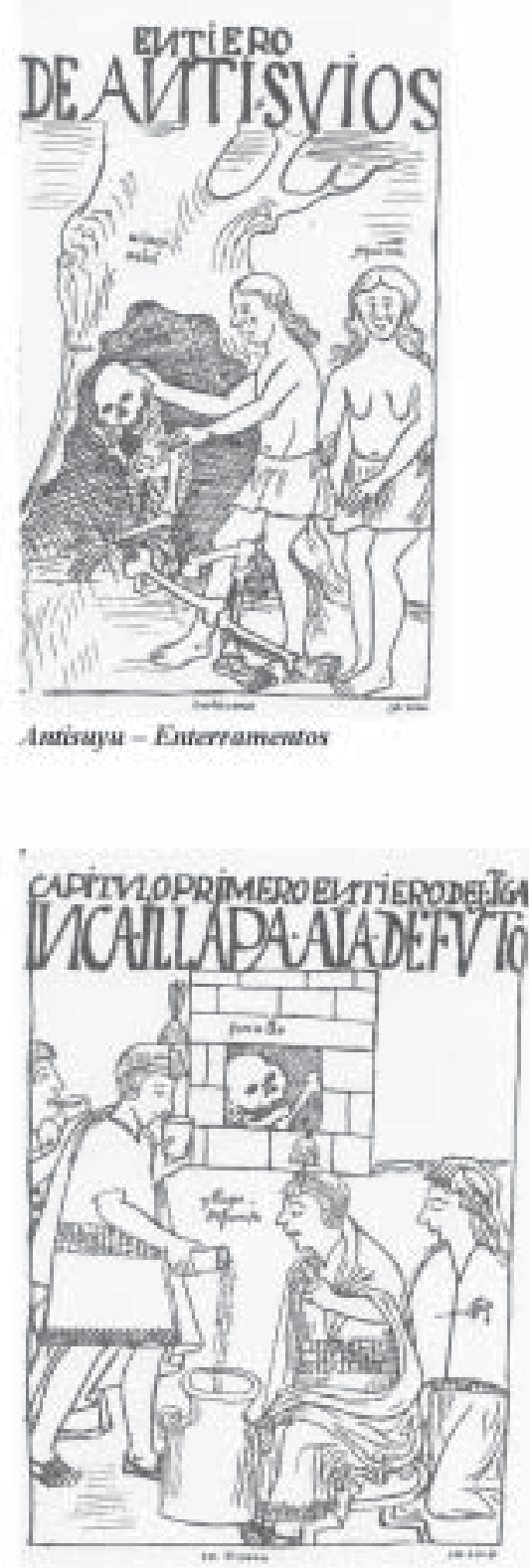

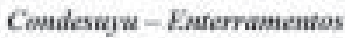


Figuri 4

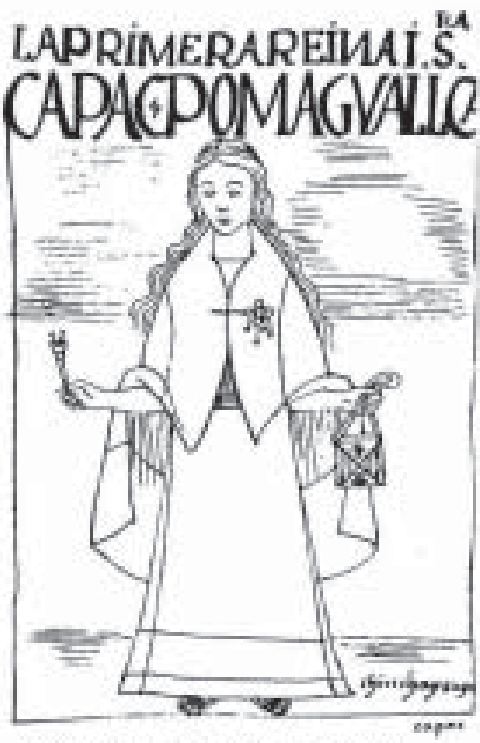

Chinchaysigu - Primeira Colla

TER 3ERA SEUTORA CADACOMETALIAMI

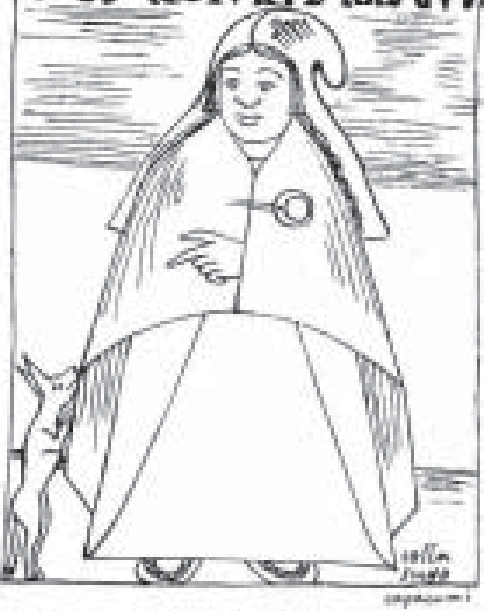

Collaswy - Terecira Calla

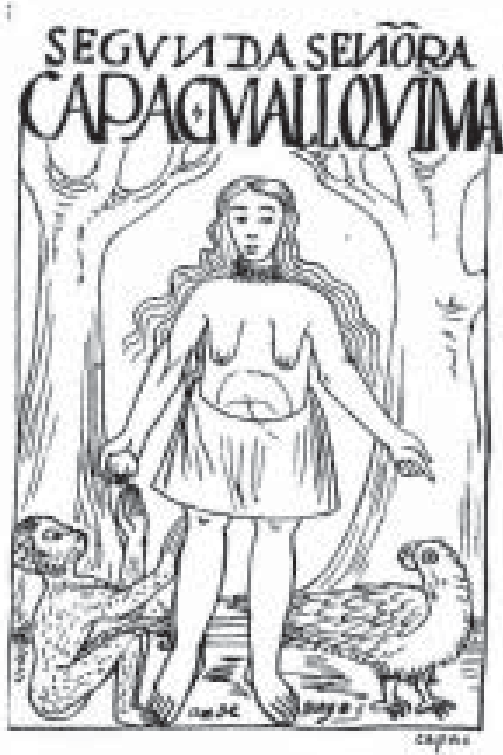

Anrisayn - Segunda Collo

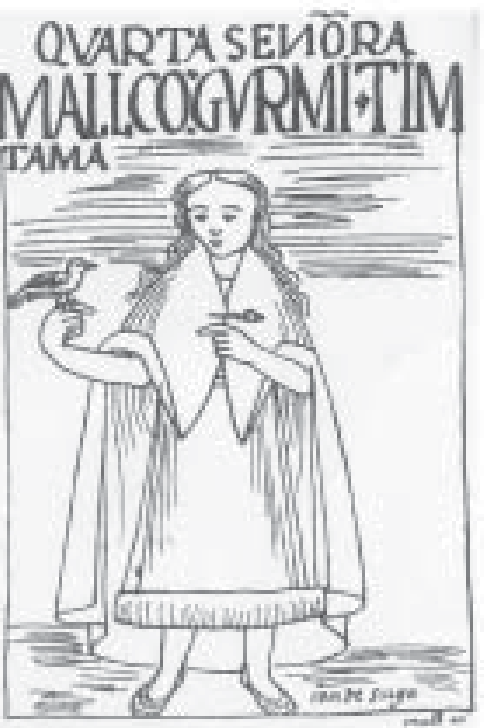

Condesayu - Quwrta Colla 
Os enterros e rituais realizados em Cuzco são, de acordo com o autor, os mais elaborados. Já em relação ao Chinchaysuyu, Collasuyu e Cuntisuyu tais rituais contêm os elementos que são esperados de qualquer ritual na região andina. Por exemplo, os habitantes desses locais alimentavam os mortos regularmente após seu falecimento, colocavam valiosas oferendas em suas tumbas (ouro, prata, folhas de coca, plumas, etc), vestiam o defunto em bonitas vestimentas e mostravam o corpo do falecido em uma procissão antes do seu enterro e subseqüente enterros que ocorriam anualmente. O mesmo, porém, não acontecia com os habitantes do Antisuyu como pode ser observado nesta passagem do manuscrito:

Y ací apenas dexa el defunto que luego comiensan a comello que no le dexa carne, cino todo gueso. Luego que acaua de suspirar le bista unos bistidos de plumajes que ellos les hazen y quitan la plumería y le desnudan y le lauan y comiensa a hazer carnesería e(n) ellos. ${ }^{28}$

Para os Incas, de acordo com Wachtel ${ }^{29}$, os ritos funerários periódicos representavam simultaneamente uma junção e disjunção em que passado e presente eram partes essenciais do processo histórico. Assim sendo, poderia ser argumentado que os Antis, ao praticarem a antropofagia, estavam interrompendo este processo histórico.

Ao longo de seu manuscrito Guaman Poma segue o mesmo padrão em diferenciar - visual e textualmente - o Antisuyu dos demais suyus como pode ser observado no caso das festas, celebrações e Huacas (figuras 5 e 6) que eram prática comum entre os povos andinos.

\section{Considerações Finais}

Como discutido acima, os Antis são claramente diferenciados nas representações pictográficas feitas por Guaman Poma. O mesmo também ocorria com outras crônicas do mesmo périodo.

\footnotetext{
${ }^{28}$ AYALA, GUAMAN POMA (1615) El Primer Nueva Corónica y Buen Gobierno. México: Siglo Vientiuno, 1980, p. 267.

${ }^{29}$ WACHTEL, NATHAN Sociedad e Ideologia. Ensayos de Historia y Antropologia Andinas. Lima, Instituto de Estudios Peruanos, 1973.
} 
Figura 5

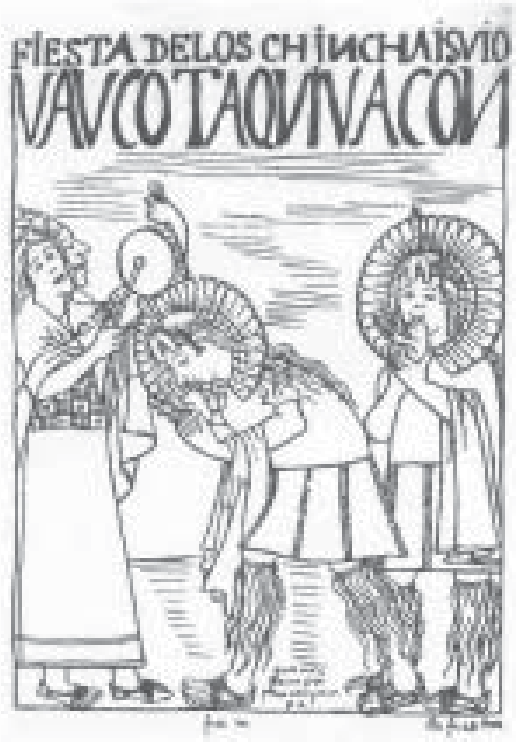

Chinchayen - Fesnas

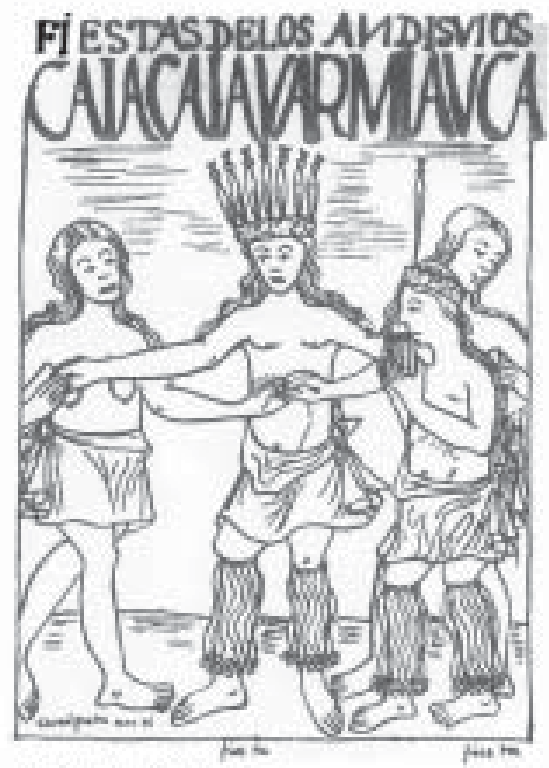

Antisuyu - Fotas

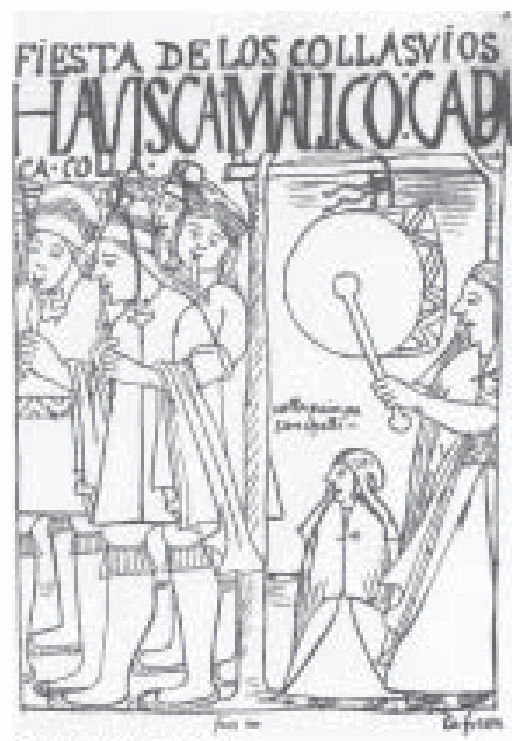

Collaswe - Festas

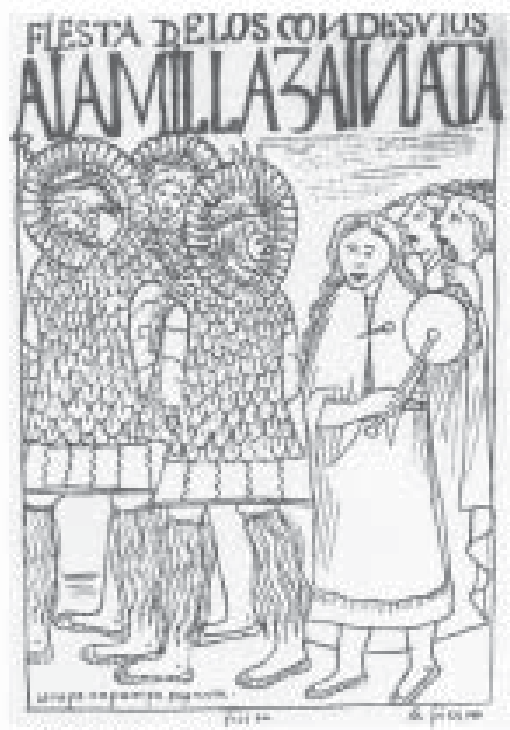

Condeszuy - Festas 
Figura 6

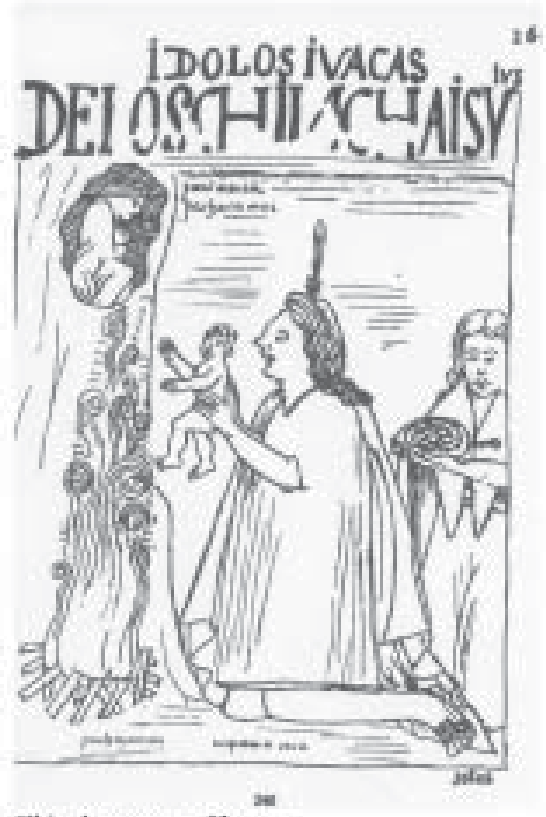

Chinchaysuys - Huacs

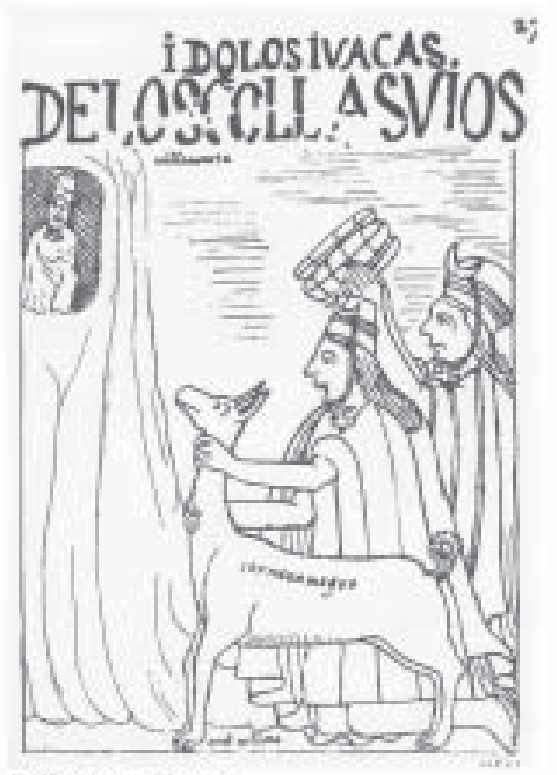

Collaseryu - Huaca

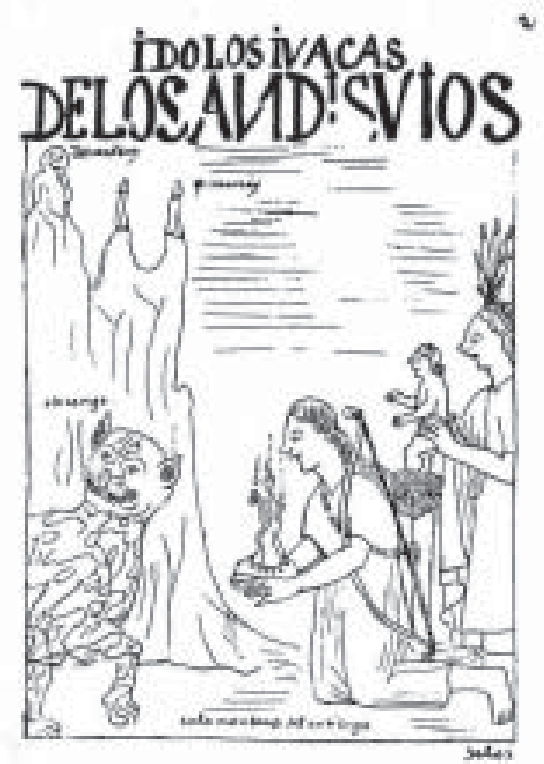

Antisuyu - lluaca

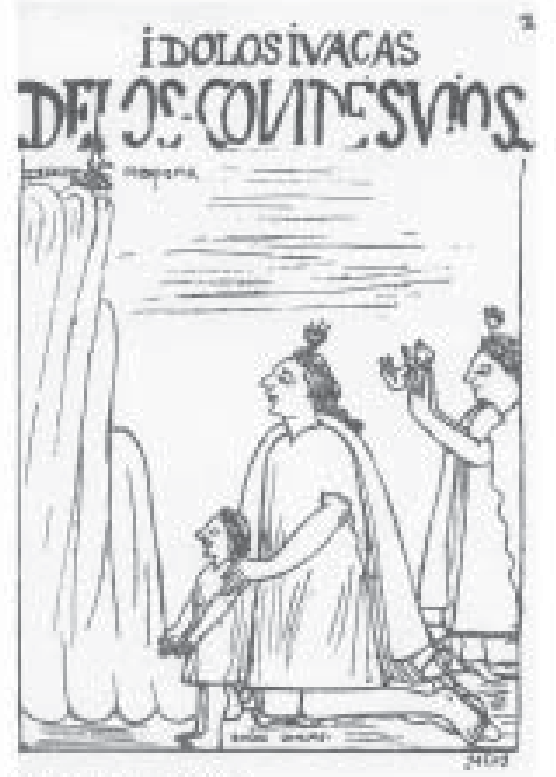

Condesuyu-Huaca 
Assim como durante o século dezesseis os espanhóis justificaram a colonização e cristianização do Peru através da idéia de que os índios nativos precisavam se tornar civilizados e serem convertidos à fé católica, os Incas tinham estratégias similares na tentativa de conquistar o Antisuyu e seus habitantes. No entanto, é bem conhecido que os Incas tinham extensos e intensos laços com os Antis (não somente relações comerciais, mas principalmente culturais), e que também o Antisuyu representava uma parte não somente complementar, mas essencial para o Tahuantinsuyu como um todo.

Com a chegada dos espanhóis, as relações e laços entre os Incas e os Antis começaram a se diluir aos poucos graças à desintegração do império que então transformou as diferenças entre Incas e Antis em um divórcio que dividiu ainda mais os povos das terras altas daqueles que viviam nas terras baixas. A partir de então, a imagem de primitivos e bárbaros relacionada aos Antis passou a ser muito mais reforçada e exagerada pelos espanhóis.

\section{Bibliografia}

ADORNO, R. Guaman Poma. Writing and Resistance in Colonial Peru. Institute of Latin American Studies, University of Texas Press, 1986.

ADORNO, R. Don Felipe Guaman Poma de Ayala: Author and Prince. In: Guaman Poma de Ayala. The Colonial Art of an Andean Author. New York: Americas Society, 1992:32-45.

FERNÁNDEZ-ARMESTO, F. Civilizations. Macmillan, 2000.

AYALA, GUAMAN POMA (1615) El Primer Nueva Corónica y Buen Gobierno. México: Siglo Vientiuno, 1980.

BROKAW, G. The Poetics of Khipu Historiography: Felipe Guaman Poma de Ayala's Nueva Corónica and the Relación de los Quipucamayos. Latin American Research Review, Vol. 38. N. 3, October 2003:111-147.

BROKAW, G. Khipu Numeracy and Alphabetic Literacy in the Andes: Felipe Guaman Poma de Ayala's Nueva Corónica y Buen Gobierno. Colonial Latin American Review, Vol. 11, N. 2, 2002:275-303.

BROTHERSTON, G. Book Of The Fourth World. Reading The Native Americas through their Literature. Cambridge University Press, 1992.

COE, M. Social Typology and the Tropical Forest Civilizations. Comparative Studies in Society and History, 1961, 4 (1):65-85. 
CUMMINS, T. The Unconfortable Image: Pictures and Words in the Nueva Corónica y Buen Gobierno. In: Guaman Poma de Ayala. The Colonial Art of an Andean Author. New York, Americas Society, 1992:46-59.

DILLEHAY, T. D. \& NETHERLY, P. (Orgs.) La Frontera del Estado Inca. Quito: Editorial Abya-Yala, 1998.

FRASER, V. The artistry of Guaman Poma. Res 1996, 29-30:269-289.

GADE, D. W. Comercio y Colonizacion en la Zona de Contacto entre la Sierra y las Tierras Bajas del Valle del Urubamba, Peru. In: Actas y Memorias del XXXIX Congreso Internacional de Americanistas. Lima: Instituto de Estudios Peruanos, 1972, Vol. 4: 207-221.

KROEBER, A. L. Culture. A Critical Review of Concepts and Definitions. New York: Vintage Books, 1952.

LÓPEZ-BARALT, M. From Looking to Seeing: the Image as Text and the Author as Artist. In: Guaman Poma de Ayala. The Colonial Art of an Andean Author. New York: Americas Society, 1992: 14-31.

LÓPEZ-BARALT, M. La Persistencia de las Estructuras Simbólicas Andinas en los Dibujos de Guamán Poma De Ayalla. Journal of Latin American Lore, USA, 1979, 5, 1:83-116.

LEVELLIER, R. Los Incas. Sevilla: Escuela de Estudios Hispano-Americanos de Sevilla, 1956.

LEVIS-STRAUSS, C. Strutural Anthopology. London, Penguin Books, 1963.

MEGGERS, B. J. Environmental Limitations on the Development of Culture. American Anthropologist, New Series, 1954, Vol. 56, N. 5, Part 1:801-824.

MYERS, T. P. Agricultural Limitations of the Amazon in theory and Practice. The Humid Tropics. World Archaeology. Jun., 1992, Vol. 24, No. 1: 82-97.

MORRIS, C. Signs of Division, Symbols of Unity: Art in the Inka Empire. In: Levenson, J. (Ed.) Circa 1492: Art in the Age of Exploration. National Gallery of Art, 1991: 521-528.

PÄRSSINEN, M. \& KORPISAARI, A. (eds.) Western Amazonia. Amazônia Ocidental. Multidisciplinary Studies on Ancient Expansionistic Movements, Fortifications and Sedentary Life. Renwall Institute Publications 14. University of Helsinki, 2003.

PARSSINEN, M. Tawantinsuyu. El Estado Inca y su Organización Política. Lima: Instituto Francés De Estudios Andinos, 1992. 
PRATT, M. L. Imperial Eyes: Travel Writing and Transculturation. London: Routledge, 1992.

SAIGNES, T. Los Andes Orientales: Historia de un Olvido. Cochabamba: Instituto Francés de Estudios Andinos de la Realidad Económica y Social, 1985.

SANTOS, F. Etnohistoria de la Alta Amazônia. Siglos XVI-XVIII. Equador: Editora Abya-Yala, 1992.

STEWARD, J. (Ed.) Handbook of South American Indians. Washington D.C.: Smithsonian Institution, 1948.

TAYLOR, A. C. The Western Margins of Amazonia from the Early Sixteenth to Early Nineteenth Century. In: SALOMON, F. \& Schwartz, S. B. (Eds.). The Cambridge History of Native Peoples of Americas, South America III.Cambridge University Press, 1999:188-256.

TAYLOR, A. C. Géneseis de un Arcaísmo: La Amazonia y su Antropología. In: Bernand, C. (Org.) Descubrimiento, Conquista y Colonización de América a Quinientos Años. México: Fondo de Cultura Económica, 1994.

WACHTEL, N. Sociedad e Ideologia. Ensayos de Historia y Antropologia Andinas. Lima: Instituto de Estudios Peruanos, 1973.

ZUIDEMA, T. El Sistema de Ceques del Cuzco. La Organización de la Capital de los Incas. Lima: Fondo Editorial de la PUC-Peru, 1995. 